\title{
Herpes simplex virus blocks apoptosis by precluding mitochondrial cytochrome $c$ release independent of caspase activation in infected human epithelial cells
}

\author{
Martine Aubert • Lisa E. Pomeranz • John A. Blaho
}

Published online: 31 October 2006

(C) Springer Science + Business Media, LLC 2006

\begin{abstract}
Expression of HSV-1 genes leads to the induction of apoptosis in human epithelial HEp-2 cells but the subsequent synthesis of infected cell protein prevents the process from killing the cells. Thus, viruses unable to produce appropriate prevention factors are apoptotic. We now report that the addition of either a pancaspase inhibitor or caspase-9specific inhibitor prevented cells infected with an apoptotic HSV-1 virus from undergoing cell death. This result indicated that HSV-1-dependent apoptosis proceeds through the mitochondrial apoptotic pathway. However, the pancaspase inhibitor did not prevent the release of cytochrome $c$ from mitochondria, implying that caspase activation is not required for this induction of cytochrome $c$ release by HSV-1. The release of cytochrome $c$ was first detected at 9 hpi while caspase-9, caspase-3 and PARP processing were detected at 12 hpi. Finally, Bax accumulated at mitochondria during apoptotic, but not wild type HSV-1 infection. Together, these findings indicate that HSV-1 blocks apoptosis by precluding mitochondrial cytochrome $c$ release in a caspaseindependent manner and suggest Bax as a target in infected human epithelial cells.
\end{abstract}

Keywords HSV-1 - Caspase-9 - Cytochrome $c \cdot$ Bax

M. Aubert · L. E. Pomeranz · J. A. Blaho $(\bowtie)$

Department of Microbiology, Mount Sinai School of Medicine, One Gustave L. Levy Place, Box 1124, New York, NY

10029-6574, USA

e-mail: john.blaho@mssm.edu

Present address:

M. Aubert

Program in Infectious Diseases, Fred Hutchinson CRC,

Seattle, WA, USA

L. E. Pomeranz

Laboratory of Molecular Genetics, The Rockefeller University,

New York, NY, USA

\section{Introduction}

Apoptosis or programmed cell death is a tightly regulated, irreversible process usually resulting in the demise of the cell. This process is activated during normal development and by diverse stimuli that disturb cell metabolism and physiology [1]. Cells undergoing apoptosis show classical morphological changes which include membrane blebbing, nuclear and cytoplasmic condensation, and endonucleosomal DNA cleavage [2]. There are two major routes through which apoptosis is triggered \{reviewed in [3] . The first, the intrinsic pathway, involves the mitochondria. When this pathway is triggered, cytochrome $c$ is released from the mitochondria into the cytoplasm where it associates with the apoptosis protease-activating factor 1 (Apaf-1), allowing the recruitment of the initiator caspase-9 to form the apoptosome. This series of events leads to the direct activation of caspase$9[4,5]$. The second, extrinsic, pathway involves signaling through death receptors such as that for tumor necrosis factor or Fas ligand. Signaling through death receptors results in the assembly of the death-inducing signaling complex (DISC) with recruitment of the pro-form of initiator caspase8 through adaptor death domain-containing proteins, leading to activation of the procaspase by autoproteolysis. Finally, both pathways converge at the activation of downstream effector caspases, such as caspase- 3 \{reviewed in [6]\}. In some cases, the death receptor and mitochondrial pathways are interconnected via the activation of the Bcl-2-family member protein, Bid [7, 8], where caspase- 8 cleaves Bid, generating activated $\mathrm{tBid}$ which triggers the release of cytochrome $c$ [9].

Apoptosis is also an important cellular response to virus infection and many viruses, especially the large DNA viruses, have evolved mechanisms to block the process from killing infected cells \{reviewed in [10]\}. Recently, a large body of information has been generated which describes 
apoptosis during herpes simplex virus 1 (HSV-1) infection $\{$ reviewed in [11]\}. Briefly, HSV-1 triggers apoptosis and then later infected cell proteins block the process from killing the cell, thus modulating the cell death program \{reviewed in [12]\}. While the induction of apoptosis by HSV-1 occurs early and only IE gene expression is essential for the viral induction process [13], the specific pathways through which HSV-1-dependent apoptosis proceeds remain unknown. HSV-1 activates the apoptotic program in a cell type-dependent manner [14-16], and several groups have demonstrated that HSV-1 has the ability to prevent apoptosis induced by diverse stimuli, such as staurosporine (STS) [17], sorbitol-mediated osmotic shock [18], hyperthermia and thermal shock [19], exposure to ceramide, tumor necrosis factor alpha (TNF- $\alpha$ ), or anti-Fas antibody $[14,20]$, and ethanol [21], as well as cytotoxic T lymphocytes [21]. Cellular [22-24] and several viral gene products were shown to play a role in preventing apoptosis induced by the virus. The HSV-1 Us 3 , gJ, and ICP6 proteins and LAT RNA are capable of decreasing apoptosis induced by either virus infection or exposure to various chemical stimuli in the absence of other viral functions [25-29]. Koyama and Adachi originally showed that apoptosis occurred during wild type HSV-1 infection when de novo protein synthesis is blocked [30]. Additionally, infection by replication-deficient viruses deleted for the genes encoding either ICP27 [31] or ICP4 [32], which do not make late viral proteins, results in apoptosis in susceptible cell types such as HEp-2 [19, 33, 34]. Thus, such viruses can trigger but not prevent cell death and are termed apoptotic viruses [35]. Finally, it was shown that during the course of HSV-1 infection, there is an apoptosis "prevention window" between 3 and $6 \mathrm{~h}$ post infection (hpi) in which infected cell antiapoptotic factors are produced $[12,17,35]$. However, the exact process by which the virus manipulates the cell is not known.

In this study, we examined the sequence of events that occurs during HSV-1-dependent apoptosis. We show that HSV-1 induced apoptosis through the apoptosome by triggering the release of cytochrome $c$ and the subsequent activation of caspase-9 in human epithelial HEp-2 cells. The release of cytochrome $c$ was first detected at 9 hpi and caspase-9, caspase-3 and PARP processing were detected at $12 \mathrm{hpi}$. Viral infection performed in the presence of either the pancaspase inhibitor $\mathrm{z}$-VAD-fmk or the caspase9 specific inhibitor z-LEHD-fmk prevented cells infected with apoptotic HSV-1 from undergoing cell death. However, the pancaspase inhibitor did not prevent the release of cytochrome c, suggesting that caspase activation is not required for the triggering of apoptosis by HSV-1. Finally, Bax accumulated at mitochondria during apoptotic, but not wild type HSV-1 infection. Together, these findings imply that HSV-1 blocks apoptosis by targeting Bax and preclud- ing mitochondrial cytochrome $c$ release in human epithelial cells.

\section{Materials and methods}

Cell lines and viruses

All cells were maintained in Dulbecco's modified Eagle's medium (DMEM) containing 5\% fetal bovine serum. HEp-2 cells are human carcinoma cells which were obtained from the American Type Culture Collection (Rockville, Md.). HSV-1(KOS1.1) is the wild type parental virus of the replication deficient virus HSV-1(vBS $\Delta 27)(\Delta 27)[31]$ used in this study. The infections were performed at $37^{\circ} \mathrm{C}$ and all comparative infections were done at the same multiplicity of infection (MOI) of 5 or 10 plaque forming units (PFU) per cell as indicated. These MOIs were high enough to insure that virus was in excess compared to the number of cells, therefore assuring that $100 \%$ of the cells were infected.

\section{Pharmacological induction and inhibition of apoptosis}

To induce apoptosis, HEp-2 cells were either infected with the replication defective virus HSV-1(vBS $\Delta 27)$ or treated with chemical reagents for the times indicated. Apoptosis was chemically induce with either $10 \mu \mathrm{g} / \mathrm{ml}$ cycloheximide (CHX, Sigma) and $10 \mathrm{ng} / \mathrm{ml}$ TNF- $\alpha$ (Sigma) or $1 \mu \mathrm{M}$ staurosporine (STS, Sigma). DNA strand breaks were labeled with fluorescein-conjugated dUTP using terminal deoxynucleotide transferase (Boehringer Mannheim) as recommended by the vendor and visualized by fluorescence microscopy (TUNEL) as described below. The percentage of apoptotic cells was determined by counting the number of TUNEL positive cells, dividing that by the total number of cells (both TUNEL positive and negative), and multiplying by 100. Caspase inhibitors (z-VADfmk, z-LEHD-fmk, z-DEVD-fmk, and z-LETD-fmk) were obtained from Calbiochem and used at concentrations of $100 \mu \mathrm{M}$, as described [17]. In control studies, z-LEHDfmk and z-LETD-fmk at these concentrations blocked STSand TNF- $\alpha$ plus CHX-dependent apoptosis, respectively, as expected.

\section{Plasmid transfections}

Recombinant plasmid pJB55 contains approximately $2.3 \mathrm{kbp}$ of HSV-1(F) genomic DNA cloned into pGEM3Z and expresses ICP27 from its own promoter. pSVV-ORF4 contains $1420 \mathrm{bp}$ of the simian varicella virus (svv) genome cloned into pCI-neo, expresses svv ICP27 (ORF 4) from 
its own promoter, and was generously provided for these studies by R. Mahalingam (University of Colorado Health Sciences Center) [36]. HEp-2 cells were transfected with approximately $2.5 \mu \mathrm{g}$ of plasmid DNA using the DOTAP transfection reagent (Roche) as described previously [37].

Cell extract preparations, denaturing gel electrophoresis, and transblotting

Cell cultures were harvested at the times post infection (p.i.) or treatment indicated and whole infected cell extracts were made as described previously [17]. Protein concentrations were measured using a modified Bradford assay (BioRad) as recommended by the vendor. Equal amounts of infected cell proteins $(50 \mu \mathrm{g})$ were separated in denaturing $15 \%$ DATD-acrylamide gels and electrically transferred to nitrocellulose membranes in a tank apparatus (BioRad), prior to immunoblotting with various primary antibodies. Unless otherwise noted in the text, all biochemical reagents were obtained from Sigma. Nitrocellulose membranes were obtained directly from Schleicher and Schuell. Protein molecular weight markers and all tissue culture reagents were purchased from Life Technologies.

\section{Immunological reagents}

The following primary antibodies were used to detect viral proteins: (i) rabbit anti-thymidine kinase (TK) polyclonal antibody (gift of Bernard Roizman) (early protein marker), (ii) H1119, mouse anti-ICP27 (immediate early protein marker), (iii) H1114, mouse anti-ICP4 (immediate early protein marker), (iv) RGST22, rabbit anti-ICP22 (immediate early protein marker) [38] and (v) H1104, mouse anti-glycoprotein $\mathrm{C}(\mathrm{gC})$ (late protein marker) monoclonal antibodies (Goodwin Institute for Cancer Research, Plantation, FL). Cellular proteins were detected using anticaspase-3 (Transduction Laboratories Inc.), anti-caspase- 8 (clone B9-2), anti-caspase-9, anti-PARP, anti-cytochrome c (clone 7H8.2C12) (Pharmingen), anti-Bcl-2 (sc-7382), anti-Bax (sc-493), and anti-Bcl- $\mathrm{X}_{\mathrm{L}}$ (sc-634) (Santa Cruz Biotechnology, Inc) antibodies. Anti- $\alpha$-tubulin monoclonal antibody (DM 1A, Sigma) was used to confirm equal loading of the cell extracts (data not shown). Secondary (goat) anti-rabbit, anti-mouse and (rabbit) anti-goat antibodies conjugated with alkaline phosphatase were purchased from Southern Biotech (Birmingham, AL). Secondary (goat) anti-mouse and anti-rabbit antibodies conjugated with horseradish peroxidase were obtained from Amersham. Fluorescein isothiocyanate-conjugated anti-rabbit $\operatorname{IgG}$ heavy plus light chains $(\mathrm{H}+\mathrm{L})$, tetramethylrhodamine isothiocyanate (Texas Red)-conjugated anti-rabbit $\operatorname{IgG}(\mathrm{H}+\mathrm{L})$, and Texas Red-conjugated anti-mouse $\operatorname{IgG}(\mathrm{H}+\mathrm{L})$ were purchased from Vector Laboratories (Santa Cruz, Calif.) and were used as secondary antibodies for indirect immunofluorescence.

Cytochrome $c$ release assay

The protocol for detection of cytochrome $c$ released into the cytoplasm was an adaptation from that previously described [39]. Briefly, subconfluent cells in a $75 \mathrm{~cm}^{2}$ flask (approximately $6 \times 10^{7}$ cells) were either infected (MOI $=5$ ) or treated with STS for the times indicated in the text and harvested by scrapping directly into the medium. The cells were gently pelletted by low speed centrifugation $(300 \times g)$, washed once in PBS, pelletted again, and resuspended in $100 \mu \mathrm{l}$ of $10 \mathrm{mM}$ HEPES, $\mathrm{pH} 7.4,50 \mathrm{mM} \mathrm{KCl}, 5 \mathrm{mM}$ EGTA, $5 \mathrm{mM} \mathrm{MgCl}_{2}, 1 \mathrm{mM}$ DTT, and $10 \%$ sucrose. Samples were incubated on ice for $30 \mathrm{~min}$, transferred to a Dounce homogenizer, and lysed by three strokes with a B type pestle. The solution was transferred to a $1.5 \mathrm{ml}$ tube and centrifuged $(300 \times g)$ for $10 \mathrm{~min}$ at $25^{\circ} \mathrm{C}$. The supernatant was transferred to a fresh tube and frozen on crushed dry ice for $1 \mathrm{~min}$, followed by high speed centrifugation $(14,000 \times g)$ for $10 \mathrm{~min}$ to pellet the heavy membrane fraction and mitochondria. The supernatant was removed and represented the mitochondria-depleted cytoplasmic fraction which was then immunoblotted for reactivity with anti-cytochrome $c$ antibody.

\section{Indirect immunofluorescence and microscopy}

HEp-2 cell monolayers were grown on glass coverslips in 6-well dishes at $37^{\circ} \mathrm{C}$ in DMEM with $5 \%$ fetal bovine serum $(\mathrm{FBS})$ and either infected (MOI = 5), treated with the apoptosis inducer, or both for the times indicated. Thirty minutes prior to performing immunofluorescence staining, the cells were incubated in the presence of MitoTracker (Molecular Probes) which was added to the medium at a final concentration of $0.5 \mu \mathrm{M}$. At each time indicated, the cells were fixed with $2 \%$ (methanol free) paraformaldehyde in phosphatebuffered saline (PBS) for $20 \mathrm{~min}$ and permeablized with $100 \%$ acetone at $-20^{\circ} \mathrm{C}$ for $4 \mathrm{~min}$. Indirect immunofluorescence staining was performed as described previously [40]. Briefly, the cells were incubated/blocked at $4^{\circ} \mathrm{C}$ for at least $24 \mathrm{~h}$ in $1 \% \mathrm{BSA}$ containing $10 \mu \mathrm{g} / \mathrm{ml}$ of pooled human Ig (mainly IgG) (Sigma), prior to incubation with primary antibody for $1 \mathrm{~h}$. Then, a $45 \mathrm{~min}$ incubation was performed with secondary antibody diluted in 1\% BSA containing $5 \mu \mathrm{g} / \mathrm{ml}$ Hoechst DNA dye (Sigma). Finally, the cells were mounted in a $0.1 \%$ Mowoil (Sigma) with $2.5 \%$ DABCO (Sigma) used as an antibleaching agent under a fresh coverslip and sealed with nail polish. Cells were visualized on either an Olympus IX70/IX-FLA inverted fluorescence microscope or a Leica confocal laser-scanning microscope as described [40]. The percentages of apoptotic cells also were 
determined by counting the number of cells with either cytochrome $c$ released from mitochondria or Bax translocated to mitochondria, dividing those by the total number of cells, and multiplying by 100 .

\section{Results}

Herpes simplex virus 1 (HSV-1) modulates apoptosis during productive infection in human epithelial cells. The goal of this study is to define the cellular molecular mechanisms through which this process occurs. We compare cellular responses to infection by wild type virus with those of an apoptotic HSV-1 strain which triggers cell death but is unable to prevent the process from killing the cells.

Caspase-9 is processed in HEp-2 cells infected with a replication-defective, apoptotic HSV-1

Previously, we and others demonstrated that infection with certain replication-defective (apoptotic) HSV-1 viruses, such as those deleted for the regulatory ICP4 [19] or ICP27 [33] proteins, induce apoptosis in infected cells. While wild type HSV-1 triggers the cell death program [21] and caspase-3 is activated during productive infection [17], subsequently synthesized infected cell proteins act to inhibit the apoptotic process [17]. The first question we asked was whether upstream (initiator) caspases were cleaved during HSV-1 infection. Two sets of experiments were performed. In the first series, HEp-2 cells were mock-, HSV-1(KOS)-, or HSV$1(\mathrm{vBS} \Delta 27)$-infected in the presence or absence of the pancaspase inhibitor z-VAD-fmk. At $18 \mathrm{hpi}$, cells were stained with Hoechst DNA dye and processed with TUNEL reagents (Fig. 1(A)) as described in Materials and Methods. Cells infected with the replication-defective virus vBS $\Delta 27$ showed classical apoptotic morphologies such as nuclear fragmentation and chromatin condensation, observed as bright, partitioned Hoechst staining of the nuclei. Additionally, all the cells infected with vBS $\Delta 27$ were positive for TUNEL staining, revealing the presence of cleaved genomic DNA in those cells. However, cells infected with vBS $\triangle 27$ which were treated with the pancaspase inhibitor z-VAD-fmk during infection had no apoptotic morphologies or DNA fragmentation. Nearly all of the mock- and wild type KOS virusinfected cells had uniformly stained nuclei with no sign of condensation. These results demonstrate that the apoptotic features observed in cells infected with the replicationdefective vBS $\Delta 27$ virus were dependent upon caspase activities. A few of the KOS-infected cells showed Hoechst staining characteristic of apoptotic cells. This represents the earlier noted [17] minimal level of apoptosis associated with this particular virus strain due to the competing induction and prevention processes [11]. Interestingly, certain KOS-infected cells had slight but detectable TUNEL staining which may represent terminal transferase labeling of replicating viral DNA. Importantly, vBS $\Delta 27$ does not synthesize viral DNA in these cells [35]. It should be noted that the vBS $\Delta 27$ repair virus (generated by the reintroduction of the ICP27 gene into defective vBS $\Delta 27$ ) does not induce any apoptotic morphologies seen with the vBS $\Delta 27$ deletion virus [33]. Thus, all phenotypes associated with vBS $\Delta 27$ result solely from the absence of the ICP27 gene. In addition, earlier detailed studies from our laboratory showed that a series of 10 different ICP27 mutant viruses induced the same apoptotic phenotype as vBS $\Delta 27$ [35], indicating that unlikely gain-of-function mutations elsewhere in the viral genome are not the culprit.

In the second series of experiments, we performed immunoblot analyses to determine whether induction of caspase- 8 or caspase- 9 was involved in the HSV-1-dependent apoptosis process. HEp-2 cells were either mock-infected, infected with vBS $\triangle 27$, or KOS-infected with and without the protein synthesis inhibitor cycloheximide (CHX). As positive controls for the detection of caspase- 9 and caspase- 8 processing, mock-infected cells were treated with staurosporine (STS) and TNF- $\alpha$ in the absence or presence of CHX. Cell extracts were made at $24 \mathrm{~h}$ post infection or treatment and immunoblot analyses (Fig. 1(B)) to detect caspase, as well as PARP, processing were performed as described in Material and Methods. In this system, anti-caspase- $3,-8$, and -9 antibodies react with procaspase forms and loss of the procaspase indicates cleavage.

As expected, complete PARP cleavage was detected in the control HEp- 2 cells treated with either STS or TNF- $\alpha$ plus CHX since the full length $(116,000 \mathrm{~mol} \mathrm{wt})$ form of PARP disappeared while the processed $(85,000 \mathrm{~mol} \mathrm{wt})$ form was detected (Fig. 1(B), lane 3 and 4). These cells had complete loss of procaspase-3. Cells that were infected with vBS $\Delta 27$ or KOS in the presence of CHX also had significant PARP and procaspase- 3 cleavage (lane 5 and 6). Procaspase- 9 was processed in the vBS $\triangle 27$ and KOS plus CHX cells while KOS alone had a level similar to mock (compare lane 5 and 6 with 7 and 8). Only the mock-infected cells treated with TNF$\alpha$ plus CHX, showed significant processing of procaspase- 8 (lane 3). Together, these data suggest that HSV-1-induced apoptosis proceeds through a caspase-9-dependent pathway.

Reduced apoptotic features in cells infected with replication-defective vBS $\Delta 27$ in the presence of caspase-9 inhibitor

The results above implicate caspase-9 in HSV-1-dependent apoptosis. To determine whether caspase- 9 processing was a critical event in the induction of apoptosis by HSV-1, infections were performed in the presence of various caspase inhibitors. HEp-2 cells were mock-infected or infected with 

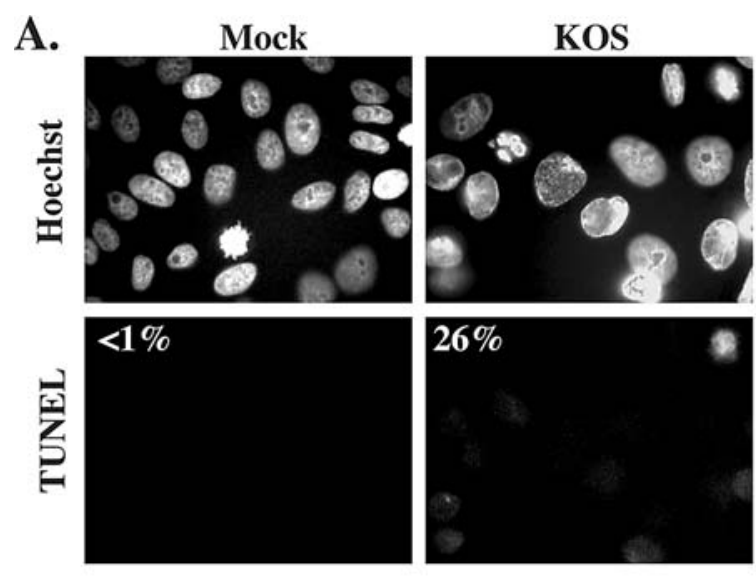

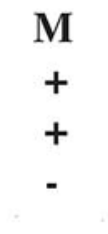

$$
\text { M }
$$

$$
-
$$$$
-
$$$$
+
$$

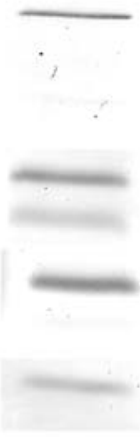

1
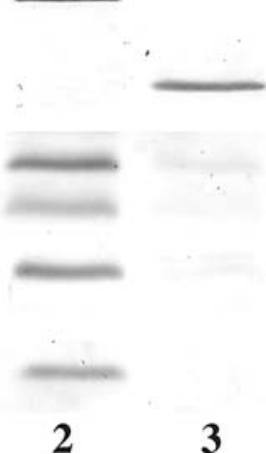

3
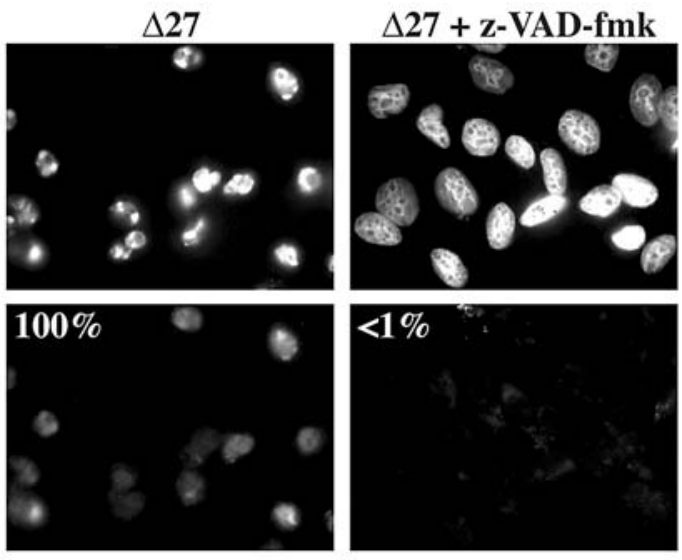

M

- $\quad$ CHX $10 \mu \mathrm{g} / \mathrm{ml}$

- $\quad$ TNF- $\alpha 10 \mathrm{ng} / \mathrm{ml}$
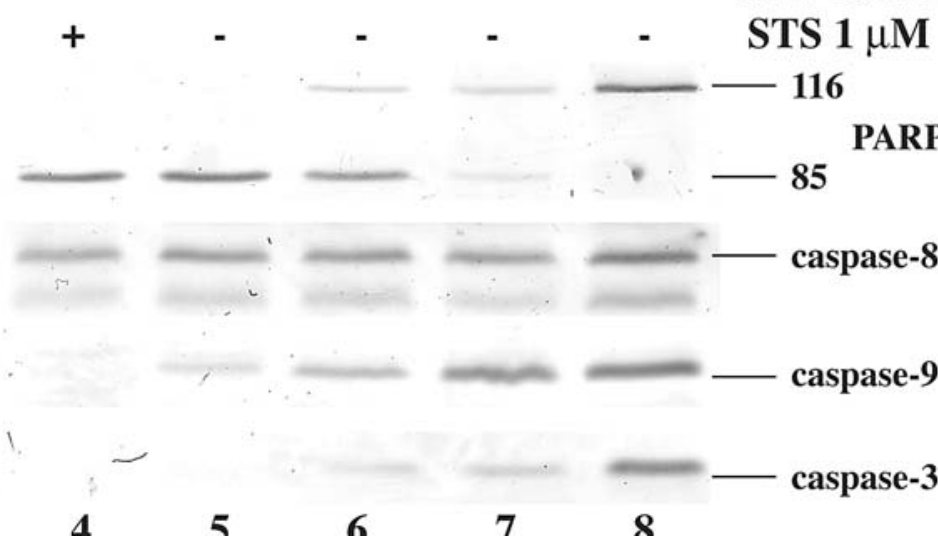

116

\section{PARP}

85

caspase-8

caspase-9

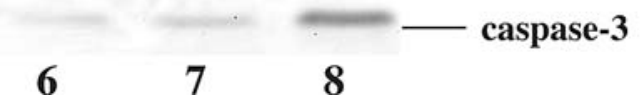

cell extracts were prepared at $24 \mathrm{hpi}$, separated in a denaturing gel, transferred to nitrocellulose, and probed with anti-PARP, -caspase-8, -caspase-9, and -caspase-3 antibodies as described in Materials and Methods. CHX was added during wild type KOS infection to block the synthesis of infected cell antiapoptotic factors. STS $(1 \mu \mathrm{M})$ and TNF- $\alpha$ (10 ng/ml) plus CHX (10 $\mu \mathrm{g} / \mathrm{ml})$ were added to mock-infected cells as positive controls for apoptosis. 116 and 85 refer to the sizes in $\mathrm{kDa}$ of unprocessed (116,000 mol. wt.) and processed PARP (85,000 mol. wt.), respectively

fected with vBS $\Delta 27$ in the absence of any inhibitor showed apoptotic morphologies including cell shrinkage and membrane blebbing, as represented by smaller cell sizes with irregular shapes/membranes. These morphologies were not observed in vBS $\triangle 27$-infected cells when either the pancaspase (z-VAD-fmk) or caspase-9 (z-LEHD-fmk) inhibitor was present during infection. These results, along with those above (Fig. 1(A)), demonstrate that vBS $\Delta 27$-induced apoptosis is caspase-dependent. However, characteristic apoptotic morphologies were still seen in vBS $\Delta 27$-infected cells (Fig. 2) in the presence of caspase- 3 and caspase- 8 inhibitors. The apoptotic phenotype seen in the presence of the caspase- 3 inhibitor could be the result of activation of another in the absence of caspase inhibitor. In contrast, the cells in- 

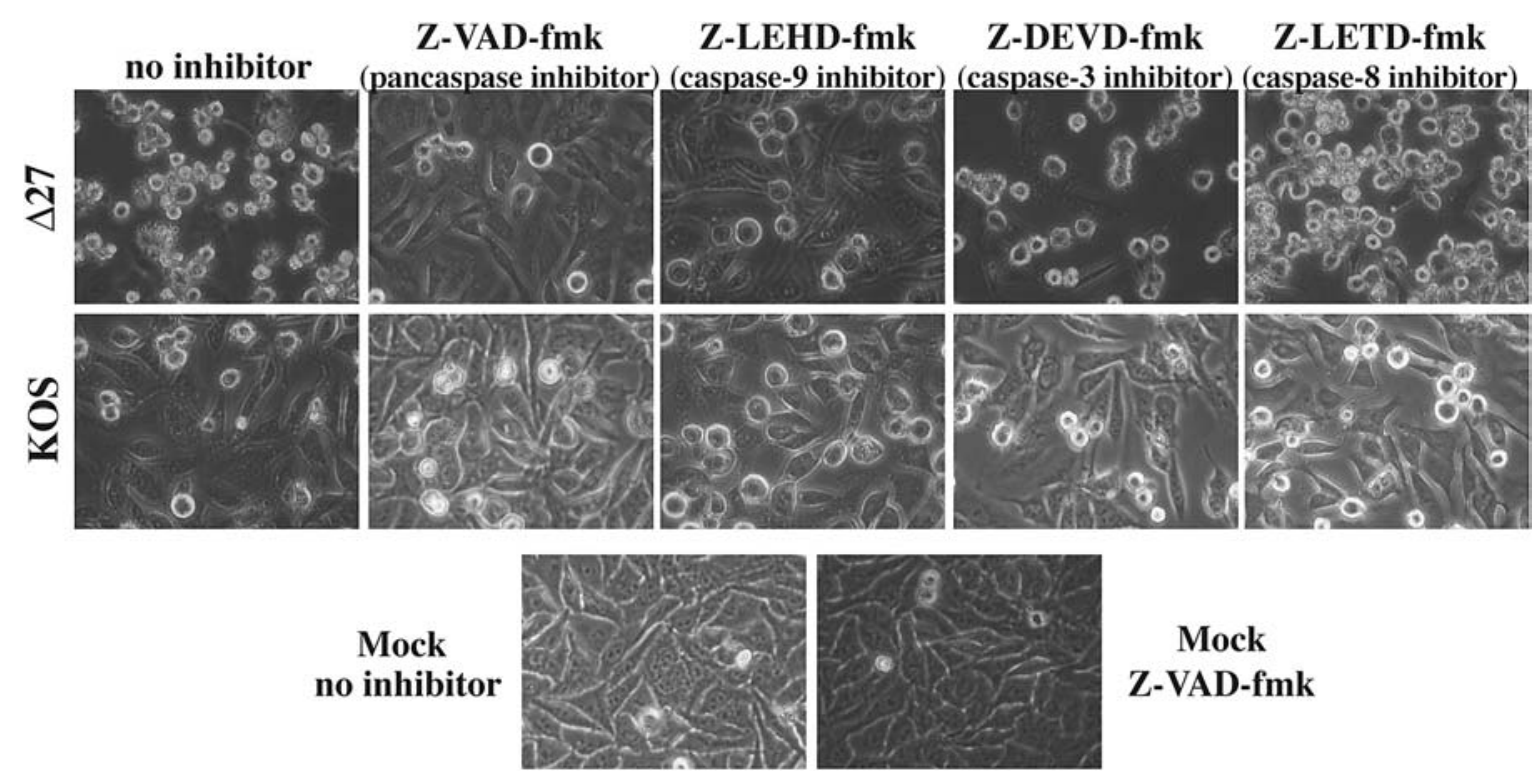

Fig. 2 Specific inhibition of caspase-9 or caspase-3 but not caspase- 8 prevents apoptosis during vBS $\Delta 27$ infection. HEp-2 cells were mock-, HSV-1(KOS)-, and HSV-1(vBS $\Delta 27)$-infected (MOI $=5$ ) in the absence or presence $(100 \mu \mathrm{M})$ of pancaspase (zVAD-fmk), caspase-9 (z-
LEHD-fmk), caspase-3 (zDEVD-fmk), and caspase-8 (z-LETD-fmk) inhibitors. Cell morphologies were observed by phase contrast microscopy at $18 \mathrm{hpi}$ as described in Materials and Methods. (Magnification, $\times 60$ )

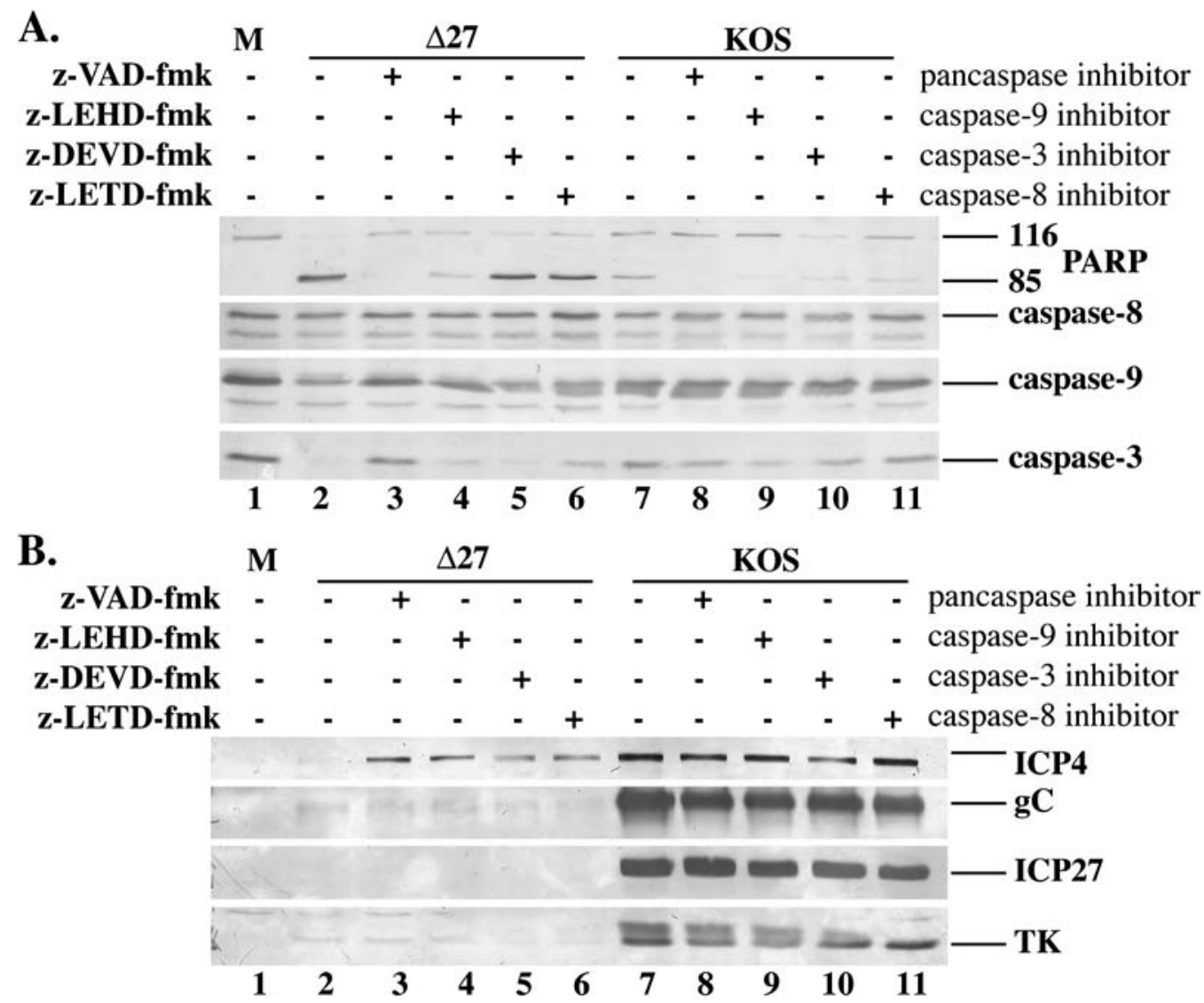

Fig. 3 Specific inhibition of caspase-9 or caspase-3 prevents death factor processing during vBS $\Delta 27$ infection. HEp-2 cells were mock (M)-, HSV-1(KOS)-, and HSV-1(vBS $\Delta 27)$-infected (MOI = 5) in the absence or presence $(100 \mu \mathrm{M})$ of pancaspase (zVAD-fmk), caspase9 (z-LEHD-fmk), caspase-3 (zDEVD-fmk), and caspase-8 (z-LETDfmk) inhibitors. Infected cell extracts of the cell shown in Fig. 2 were prepared at $18 \mathrm{hpi}$, separated in a denaturing gel, transferred to nitrocellulose, and probed with anti-PARP, -caspase- 9 , -caspase- 8 , and -caspase-3 antibodies (A) as described in Material and Methods. B. Viral protein accumulations. Immunoblotting was performed for viral proteins using anti-ICP4, -gC, -ICP27, and -TK antibodies (B) 
downstream effector caspase, such as caspase-7 [41]. It has recently been demonstrated that caspase- 3 as well as caspase7 are key mediators of mitochondrial events of apoptosis and only the cells lacking both enzymes were highly resistant to apoptosis [42].

The cells infected with vBS $\Delta 27$ in the presence of the pancaspase inhibitor (z-VAD-fmk) showed a reduction in PARP, procaspase- 9 , and procaspase- 3 processing compared to those in the absence of the inhibitor (Fig. 3(A), compare lane 2 and 3). Among the vBS $\Delta 27$-infected cells treated with specific caspase inhibitors, only those treated with the caspase-9 (z-LEHD-fmk) inhibitor (Fig. 3(A), lane 4) showed reduced PARP processing compared to the untreated, infected cells (compare lane 2 with lane 4-6). It is interest to note that although z-LETD-fmk did not block PARP processing in vBS $\triangle 27$-infected cells (lane 6), it appeared to reduce caspase-3 cleavage (compare lane 6 with 2). While addition of the pancaspase and caspase-9 inhibitors resulted in increased detection of procaspase-9 (lane 3 and 4), inhibition by z-LEHD-fmk was likely not complete since procaspase-3 was still mostly processed in its presence (lane 4). Another explanation for the cleavage of procaspase- 3 in the presence of z-LEHD-fmk could be that caspase- 3 can be cleaved by another initiation caspase at a lower level than that by caspase-9. Regardless, these results indicate that caspase-9 is cleaved during vBS $\Delta 27$ infection.

Finally, the amounts of representative viral proteins remained unchanged in the cells infected with KOS in the presence of any caspase inhibitor, compared to their absence (Fig. 3(B), compare lane 7 with 8-11). Little to no TK and $\mathrm{gC}$ was detected in vBS $\Delta 27$-infected cells. This was expected as this virus, which possesses a deletion of the $\mathrm{U}_{\mathrm{L}} 54$ gene encoding ICP27, is defective in viral early and late gene expression [31]. Consistent with previous results [35], the level of immediate early ICP4 was slight, but detectable (lane 2) and increased in the presence of the caspase-3 inhibitor (lane 5). In addition, an increased amount of ICP4 was also observed in vBS $\Delta 27$-infected cells in the presence of the pancaspase, caspase- 8 , and caspase- 9 inhibitors (compare lane 2 with $3,4,6$ ). ICP4 levels were higher in the infected cells treated with any of the four caspase inhibitors compared to the absence of inhibitors, but this was especially true with the pancaspase (z-VAD) or the caspase-9 (LEHD) inhibitor. Both inhibitors strongly prevent HSV-1 induced apoptosis and, hence, the early demise of the cells. Therefore, the observed increase of the ICP4 levels likely results from an absence of protein degradation as a result of the dismantlement of the cells due to the induction of apoptosis. These findings indicate that caspase inhibition leads to enhanced vBS $\Delta 27$ replication, as measured by viral protein accumulation. Together, these sets of data indicate that caspase-9 plays an important role in the HSV-1-dependent apoptosis induction process.
Cytochrome $c$ release during HSV-1-dependent apoptosis is independent of caspase activation

The finding that procaspase- 9 is cleaved during vBS $\Delta 27$ infection implicates the intrinsic pathway in HSV-1-dependent apoptosis. Caspase-9 activation is usually the result of cytochrome $c$ being released from the mitochondria into the cytoplasm [43]. Thus, our goal was to determine whether cytochrome $c$ was released in HSV-1-infected cells. HEp2 cells grown on coverslips were either mock-infected or infected with vBS $\Delta 27$ or KOS for $18 \mathrm{~h}$ in the presence or absence of pancaspase inhibitor (z-VAD-fmk), prior to staining with anti-cytochrome $c$ antibody, MitoTracker reagent, and Hoechst as described in Material and Methods. In parallel, mock-infected cells were treated with STS as a positive control for cytochrome $c$ release as this kinase inhibitor induces cell death through the mitochondria [44]. Thus, when apoptosis is triggered through the mitochondrial pathway, cytochrome $c$ is released from the mitochondria into the cytoplasm.

In mock-infected cells, cytochrome $c$ showed punctuate staining in the cytoplasm and perinuclear region which was similar to that of the mitochondria (MitoTracker) (Fig. 4(A)). These results are consistent with a mitochondrial localization of cytochrome $c$ in healthy cells (only $3 \%$ apoptosis). The cells treated with STS showed chromatin condensation and nuclei fragmentation when stained with Hoechst. The staining for cytochrome $c$ in those cells was not punctate and perinuclear but, rather, diffuse (96\% apoptotic). In the cells infected with the wild type KOS virus, the majority of the cells had a staining pattern similar to that seen with mockinfected cells (18\% apoptotic), indicating that cytochrome $c$ was still localized in the mitochondria. In contrast, the cells infected with the replication-defective vBS $\Delta 27$ virus showed diffuse staining of cytochrome c, suggesting the release of the molecule into the cytoplasm (55\% apoptotic).

When the intrinsic apoptotic cascade is triggered through a mitochondrial pathway, cytochrome $c$ release occurs prior to the activation of caspase- 9 and caspase-3 [43]. In an alternative pathway, activated caspase- 8 cleaves Bid, leading to cytochrome $c$ release [7-9]. To differentiate between these two pathways, we next determined whether cytochrome $c$ is released during HSV-1 infection in the absence of caspase activation. In the presence of the pancaspase inhibitor (z-VAD-fmk), all infected or treated cells showed uniform staining of nuclei (Fig. 4(B)). This demonstrated that caspase inhibition during either viral infection or STS treatment prevented the cells from undergoing chromatin condensation and nuclear fragmentation. However, when the cells were stained for cytochrome $c$, those infected with vBS $\Delta 27$ or treated with STS presented a diffuse staining pattern in the presence of the inhibitor. In contrast, the majority of the cells infected with KOS in the presence of z-VAD-fmk 
A. Mock
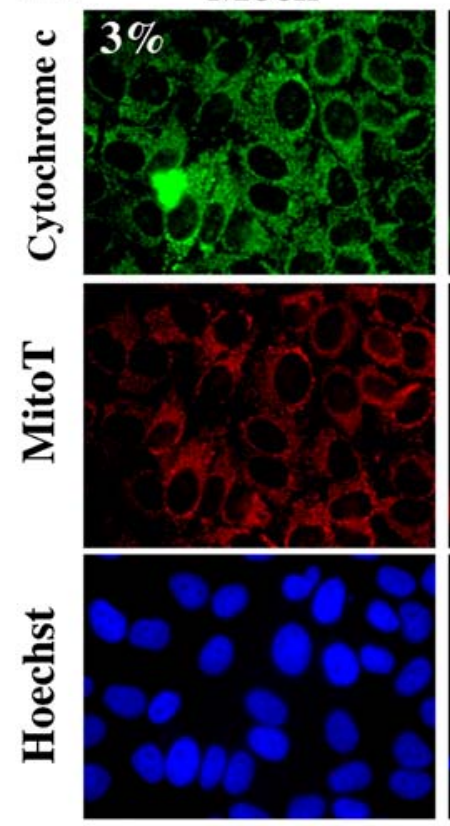

B.
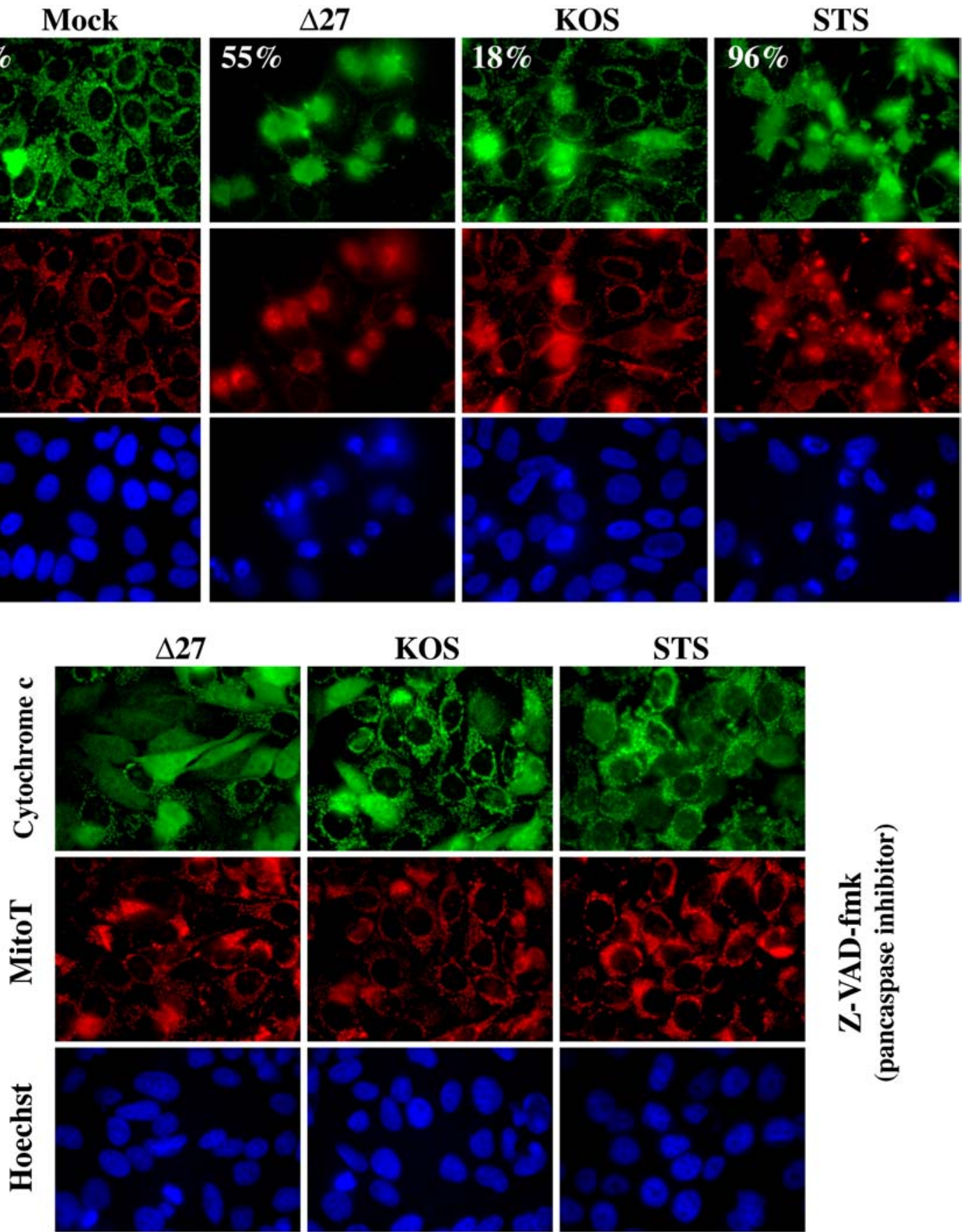

Fig. 4 Cytochrome $c$ is released from mitochondria during vBS $\triangle 27$ infection. HEp-2 cells were mock-, HSV-1(KOS)-, and HSV$1(\operatorname{vBS} \Delta 27)$-infected $(\mathrm{MOI}=5)$ in the absence $(\mathbf{A})$ or presence $(\mathbf{B})$ of $100 \mu \mathrm{M}$ pancaspase (z-VAD-fmk) inhibitor. At $18 \mathrm{hpi}$, the cells were fixed, prepared for indirect immunofluoresence using anti-cytochrome

$c$ antibodies, and the number (\%) of apoptotic cells were determined as described in Material and Methods. DNA and mitochondria were detected by fluorescence microscopy following Hoechst and MitoTracker (MitoT) staining, respectively. Magnification $(\times 100)$

showed punctate cytochrome $c$ staining (Fig. 4(B)), similar to that observed in mock- or KOS-infected cells in the absence of the caspase inhibitor (Fig. 4(A)). These data indicate that the release of cytochrome $c$ from mitochondria in vBS $\Delta 27$-infected cells does not require caspase activa- tion. In addition, active caspases are not required for wild type HSV-1 to prevent the virus-dependent cytochrome $c$ release. Taken together, our findings imply that cytochrome $c$ release during HSV-1-dependent apoptosis precedes caspase activation. 
Cytochrome $c$ release occurs prior to caspase-3, -9, and PARP processing in $\mathrm{vBS} \Delta 27$-infected cells

The results above indicated that cytochrome $c$ release occurred in the absence of caspase activation. The goal of this series of experiments was to determine the kinetics of cytochrome $c$ release and death factor processing during HSV1-dependent apoptosis. Initially, cells were infected with vBS $\Delta 27$ virus and fixed at $3,6,9$, and 12 hpi for indirect immunofluorescence using anti-cytochrome $c$ antibody along with Hoechst and MitoTracker staining. In a second set of experiments, whole cell and mitochondria-depleted cytoplasmic extracts of vBS $\Delta 27$-infected cells were made at $3,6,9,12,15,18$, and 24 hpi as described in Materials and Methods and immunoblotted using anti-PARP, -caspase-3, -caspase- 9 and -cytochrome $c$ antibodies. Controls included mock- and KOS-infected cells, as well as STS-treated cells.

At 3 and 6 hpi, vBS $\Delta 27$-infected cells had punctate cytochrome $c$ staining at the perinuclear region as well as in the cytoplasm (1\% apoptosis) (Fig. 5(A)). Diffuse cytochrome $c$ staining could be detected at 9 hpi in some of the vBS $\Delta 27$ infected cells (29\% apoptosis). At $12 \mathrm{hpi}$, approximately half of the vBS $\Delta 27$-infected cells showed cytochrome $c$ release (50\% apoptosis). These findings suggest that apoptotic triggering events prior to 9 hpi during vBS $\Delta 27$ infection initiate a process leading to mitochondrial cytochrome $c$ release. Consistent with the results above (Fig. 4), cytochrome $c$ release was detected in apoptotic, STS-treated cells $(100 \%$ apoptosis) but not in mock- or KOS-infected cells $(<1 \%$ and 7\% apoptosis, respectively) at $12 \mathrm{hpi} \mathrm{(Fig.} \mathrm{5(B)).}$

Complete PARP processing was observed at 15,18 , and 24 hpi during vBS $\Delta 27$ infection (Fig. 6(A), lane 6-8). At 12 hpi (lane 5), processing of caspase- 3 and 9 could be detected and increased from this time to 24 hpi (lane 5-8). While STS-treated cells had increased cytochrome $c$ at $6 \mathrm{~h}$ post treatment compared to mock in mitochondria-depleted cytoplasmic extracts (Fig. 6(B), compare lane 12 with 11), vBS $\Delta 27$-infected cells resembled mock at this time point (compare lane 2 with 1). In general for vBS $\Delta 27$ and STS, increased cytochrome $c$ correlated with complete PARP cleavage (lane 3-5 and 12-15). As expected, little to no PARP cleavage was observed with KOS at any time point (lane 7-10). However, we did observe increased cytochrome $c$ release with KOS at 12-24 hpi. While this may represent the level of apoptosis observed with KOS (Figs. 1-4), this seems unlikely because the extent of release observed by indirect immunofluorescence with KOS at $12 \mathrm{hpi}$ was minimal (Fig. 4). Taking these results together with those of Fig. 5, we conclude that cytochrome $c$ release occurs prior to caspase$3,-9$, and PARP processing in vBS $\Delta 27$-infected cells. These experiments help determine points in the cellular apoptotic pathways which are inhibited by wild type HSV-1. While it appears that KOS infection may lead to the release of some cytochrome $c$ and cause some PARP to be cleaved, the bulk of the proapoptotic machinery is inhibited.

Proapoptotic Bax targets mitochondria in vBS $\Delta 27$-infected cells

The findings above imply that HSV-1-dependent apoptosis observed during vBS $\Delta 27$ infection initiates by the release of cytochrome $c$ from mitochondria followed by the activation of caspase- 9 and -3 , ultimately leading to complete PARP processing as well as chromatin condensation, cell shrinkage, and membrane blebbing. A key unanswered question is at which step in this apoptotic process do cellular factors produced during wild type HSV-1 infection act to inhibit the pathway. Therefore, our goal in this study was to investigate the behavior of certain $\mathrm{Bcl}-2$ family members during HSV-1 infection. Two sets of experiments were performed. In the first series, we focused on proapoptotic Bax which is known to translocate to the mitochondria during most cases of apoptosis which are induced through the intrinsic pathway $[8,9,44,45]$. HEp- 2 cells were mock-, KOS-, and vBS $\Delta 27-$ infected. At 6 and $18 \mathrm{hpi}$, cells were fixed and prepared for indirect immunofluoresence using anti-Bax antibody, as well as stained with Hoechst and MitoTracker as described in Material and Methods. At 6 hpi, Bax was evenly distributed throughout all cells (Fig. 7(A)). At 18 hpi, several vBS $\Delta 27$-infected cells had concentrated Bax staining observed at mitochondria (33\% apoptosis) compared to mock or KOS (2\% and $15 \%$ apoptosis, respectively) (Fig. 7(B)). These findings suggest that wild type HSV-1 can block the translocation of Bax to mitochondria while vBS $\Delta 27$ cannot.

In the second series of experiments, the accumulations of representative Bcl-2 family members were characterized during HSV-1 infection. HEp-2 cells were infected with KOS or vBS $\Delta 27$-infected, whole cell extracts were prepared at 3 , $6,9,12$, and $24 \mathrm{hpi}$, separated in a denaturing gel, transferred to nitrocellulose, and probed with anti-Bcl- $\mathrm{X}_{\mathrm{L}}$, -Bcl2, -Bax, -PARP, -caspase-3, -ICP4, and -gC antibodies as described in Materials and Methods. Consistent with our results above, KOS accumulated viral proteins (ICP4 and $\mathrm{gC}$ ) while vBS $\Delta 27$ did not (Fig. 8(C)) and procaspase-3 cleavage correlated with PARP processing in vBS $\Delta 27$-infected cells (Fig. 8(B), lane 5-7). No obvious change in the levels of Bax and Bcl-2 was detected with either vBS $\Delta 27$ or KOS (Fig. 8(A)). Thus, the localization of Bax we observed above (Fig. 7) with vBS $\Delta 27$ likely represents a translocation event and not an increase in newly synthesized protein. While the levels of antiapoptotic $\mathrm{Bcl}-\mathrm{X}_{\mathrm{L}}$ also remained constant at 312 hpi with vBS $\triangle 27$ and KOS (Fig. 8(A), lane 2-5 and $8-11)$, slight increases in the amounts of this protein were detected at 16 and 24 hpi (lane 6, 7 and 12,13). This was somewhat surprising and its significance remains unclear at this time. Based on the results in Figs. 7 and 8, we conclude 
Fig. 5 Cytochrome $c$ is released from mitochondria at early times during vBS $\Delta 27$ infection.

HSV-1(vBS $\Delta 27)$-infected $(\mathrm{MOI}=5) \mathrm{HEp}-2$ cells were visualized at 3-12 hpi by indirect immunofluoresence using anti-cytochrome $c$ antibody, phase contrast microscopy, and fluorescence microscopy following Hoechst and MitoTracker (Mitochondria) staining. Control mock-, HSV-1(KOS)-infected, and STS-treated cells at $12 \mathrm{hpi}$ are shown. The number (\%) of apoptotic cells were determined as described in Material and Methods

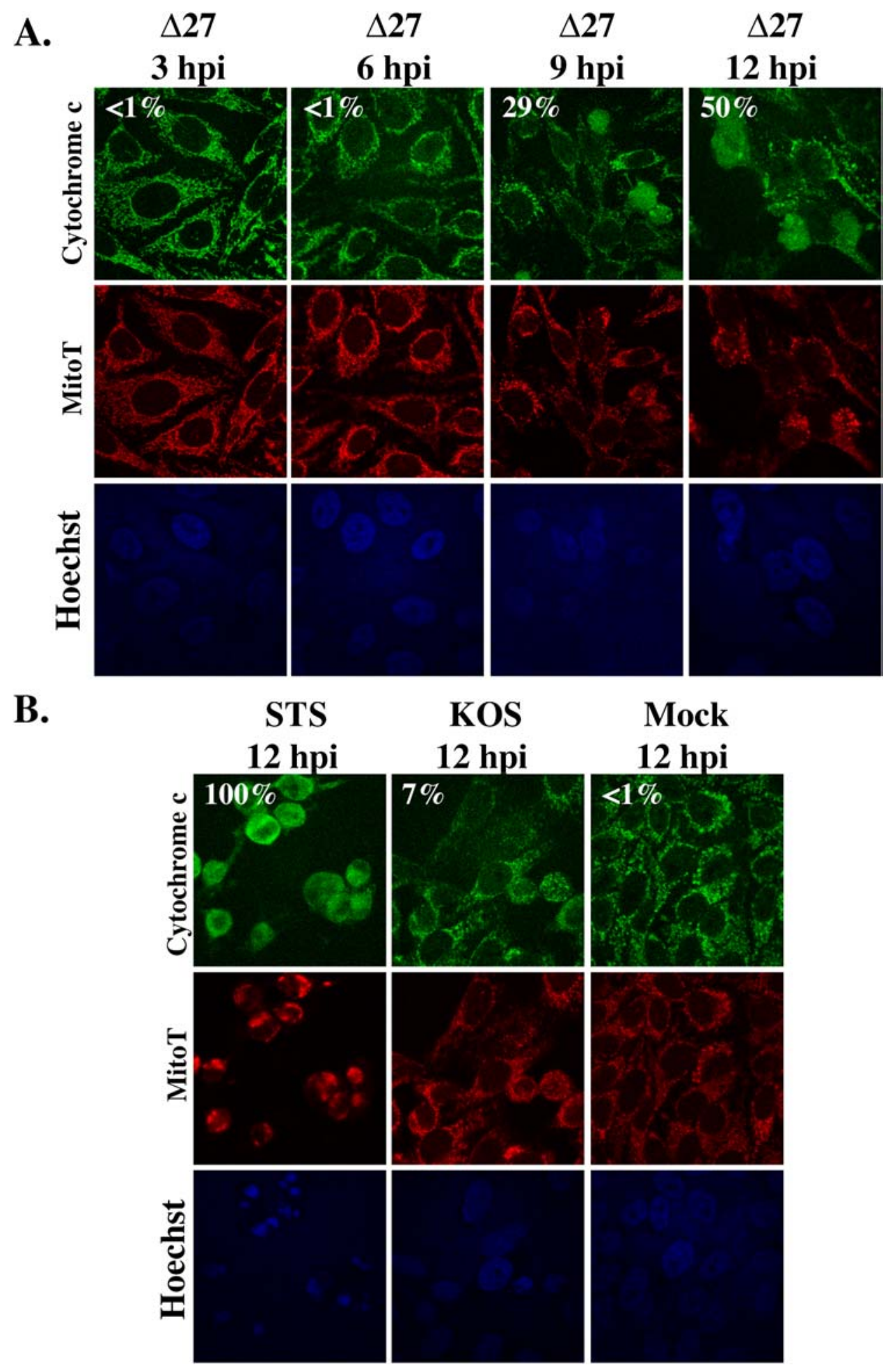

that wild type HSV-1 blocks the caspase-9 apoptotic process by preventing the translocation of proapoptotic Bax to mitochondria. We propose that infected cell factors are produced by HSV-1 which facilitate this inhibition. During vBS $\Delta 27$ infection, these Bax-antagonizing factors are not produced and the cell then dies by apoptosis.
ICP27 protein alone does not block apoptosis

Most of the experiments above consist of comparisons between wild type HSV-1 and an ICP27-null virus. Two models might explain why an HSV-1 virus deleted for the ICP27 protein is able to induce but not prevent apoptosis. First, ICP27 


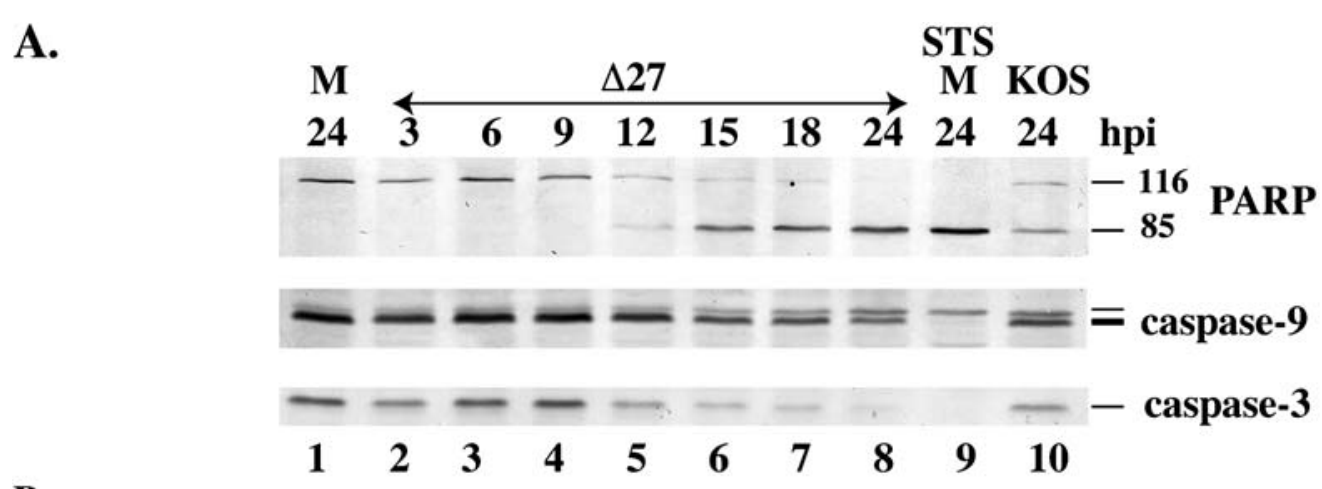

B.

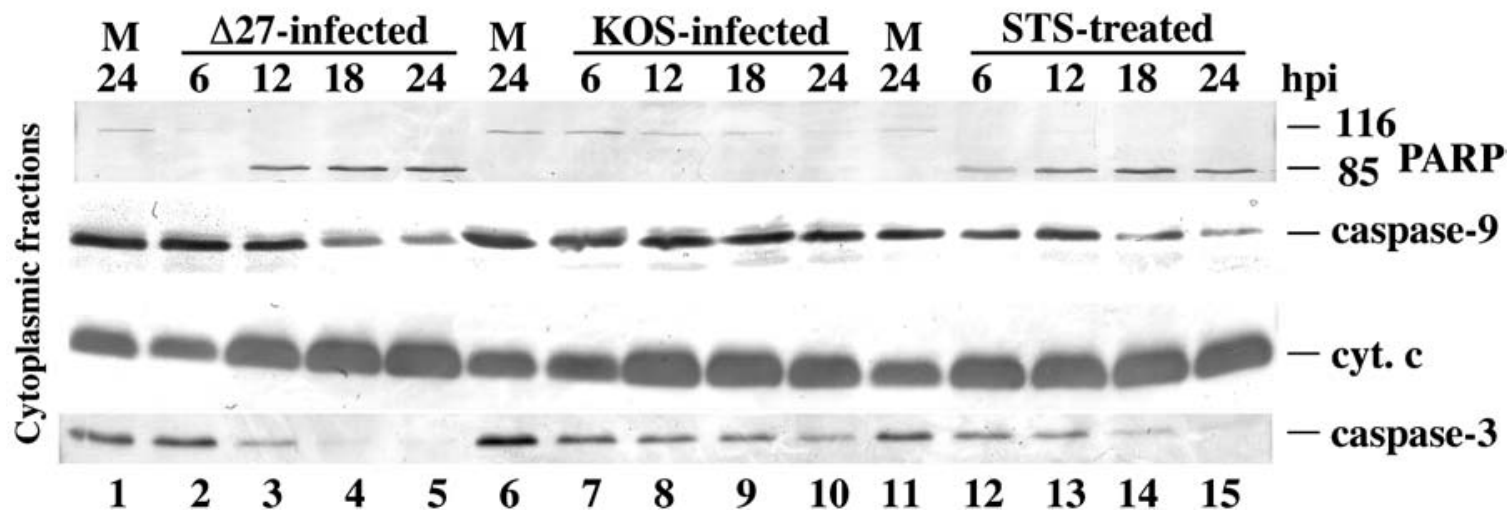

Fig. 6 A Caspase-9 activation leads to caspase-3 and PARP cleavage during vBS $\Delta 27$ infection. Cytoplasmic extracts of HSV-1(vBS $\Delta 27)-$ infected $(\mathrm{MOI}=10)$ and $(1 \mu \mathrm{M})$ STS-treated HEp-2 cells were prepared at 3-24 hpi, separated in a denaturing gel, transferred to nitrocellulose, and probed with anti-PARP, caspase- 9 , and caspase- 3 antibodies. The location of caspase- 9 is indicated. The fainter band above caspase9 was seen in all lanes and is likely attributable to nonspecific reactivity of the antibody in this blot. Controls include mock (M)- and HSV-

itself may directly inhibit apoptosis. Alternatively, ICP27 may regulate the expression of other viral or cellular factor(s) with antiapoptotic functions. The goal of this final set of experiments was to ascertain which scenario is correct. Three sets of experiments were performed (Fig. 9). In the first set, HEp-2 cells were transfected with a plasmid expressing the HSV-1 ICP27 gene as described in Materials and Methods. At $48 \mathrm{~h}$ post transfection, cells were treated with STS, prior to anti-ICP27 antibody and Hoechst staining and fluorescence microscopy. The results (Fig. 9(A)) indicate that even though cells express highly detectable levels of ICP27, they still undergo chromatin condensation in response to STS.

In the second set of experiments, plasmids containing the HSV-1 ICP27 gene and the simian varicella virus ICP27 (svv27) gene were separately transfected into HEp-2 cells, treated with STS, and whole cell extracts were immunoblotted for reactivity with anti-PARP, -ICP27, and -caspase-3 antibodies. As expected, the anti-ICP27 antibody reacted with transfected HSV-1 ICP27 but not svv27 (Fig. 9(B), compare lane 4,5 with 7,8 ). Transfections of ICP27 or svv27 into
1(KOS)-infected cells. B. Cytochrome $c$ release from mitochondria leads to caspase- 3 activation and PARP cleavage during $\Delta 27$ infection. Cytoplasmic extracts of HSV-1(vBS $\Delta 27)$-infected $(\mathrm{MOI}=10)$ and $(1 \mu \mathrm{M})$ STS-treated HEp-2 cells were prepared at 6-24 hpi, separated in a denaturing gel, transferred to nitrocellulose, and probed with anti-PARP, -cytochrome $c$ (cyto. c.), and -caspase-3 antibodies. Control mock-infected (M) cells at 24 hpi are shown

the cells did not prevent PARP and procaspase- 3 cleavage in response to STS (lane 4-6). Together, the results in Fig. 9(A) and (B) indicate that sole expression of ICP27 in unable to prevent environmentally induced apoptosis. Thus, it seems unlikely that ICP27 alone would be sufficient to generate an antiapoptotic state.

In the final set of experiments, HEp-2 cells were transfected with the plasmid expressing ICP27 and at $48 \mathrm{~h}$ post transfection, infected with vBS $\Delta 27(\mathrm{MOI}=5)$. At $6 \mathrm{hpi}$, STS was added and the cells were incubated for an additional $12 \mathrm{~h}$. Thus, at $18 \mathrm{hpi}$, the transfected/infected cells were stained with Hoechst and visualized following indirect immunofluorescence using anti-ICP27 (transfection marker) and -ICP22 (infection marker) antibodies. ICP22 is an immediate early viral protein which was used as a marker for infected cells. The results (Fig. 9(C)) indicate that infected (red) ICP27 expressing (green) cells did not show condensed chromatin features, while vBS $\Delta 27$ only infected cells (red, no green) did. It should be noted that in HEp-2 cells, the amount of ICP22 produced upon vBS $\Delta 27$ infection is much lower than that detected in wild type virus infected cells [33]. 
A.
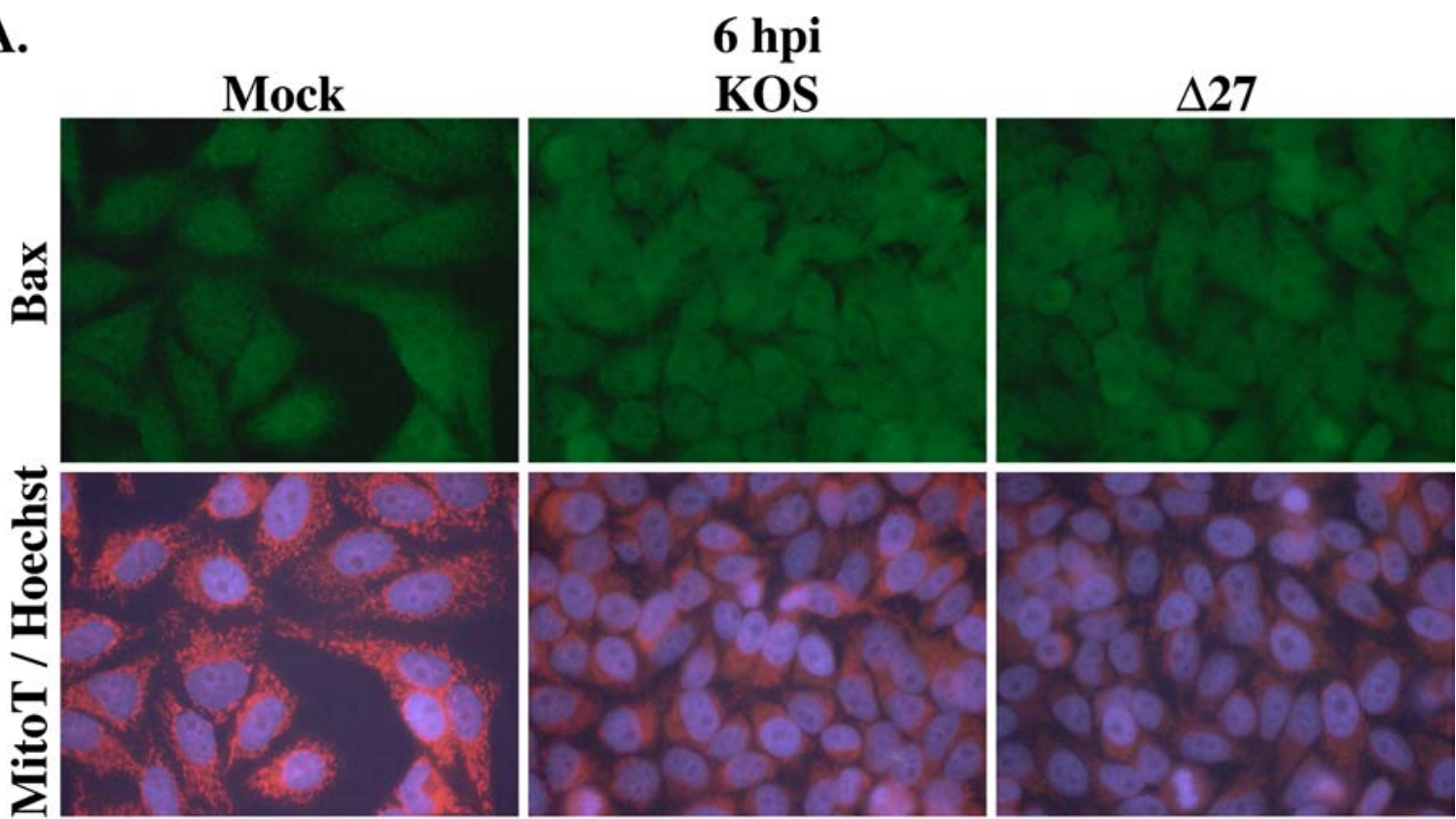

B.

18 hpi

Mock

KOS
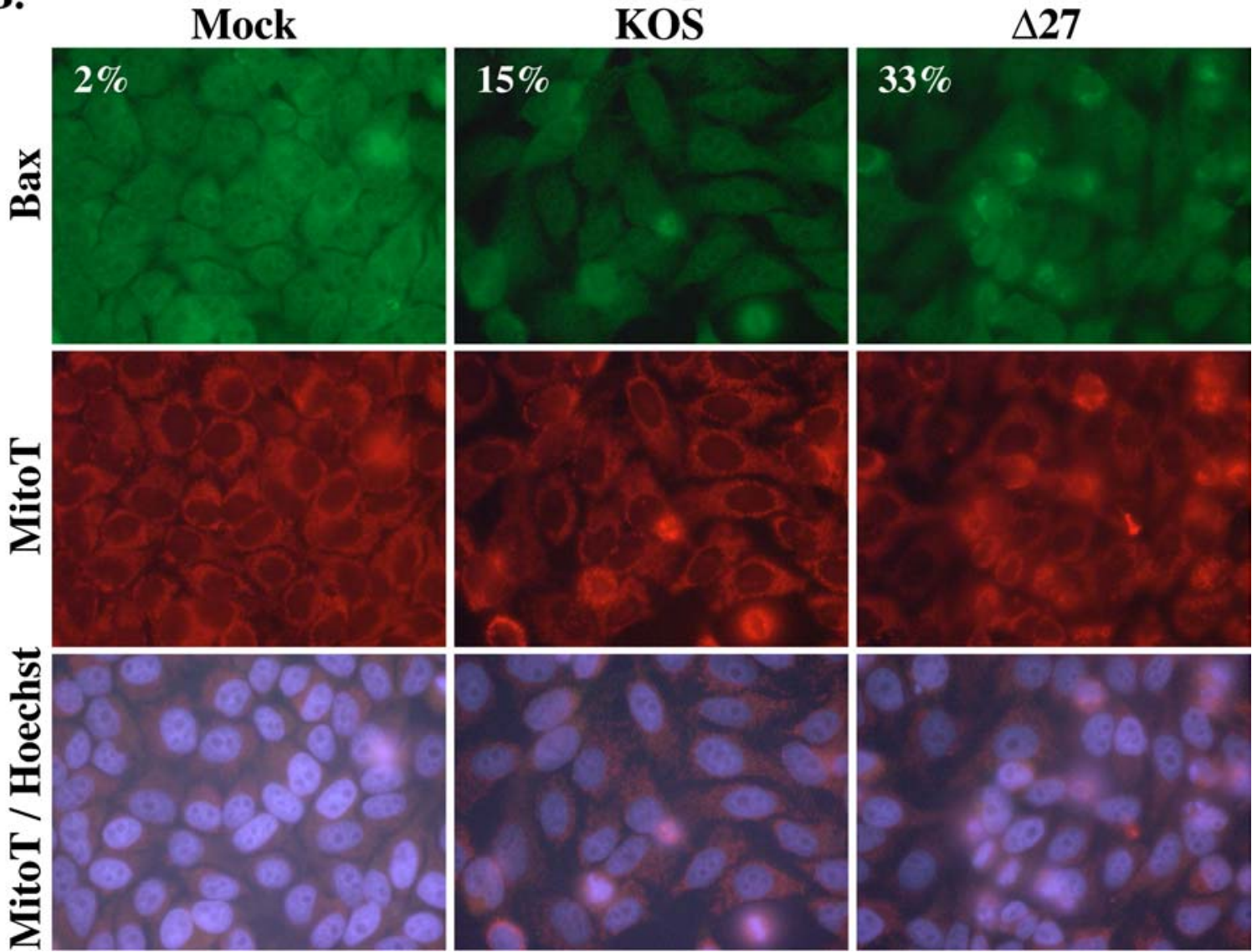

Fig. 7 Bax localizes to mitochondria during vBS $\Delta 27$ infection. HEp2 cells were mock-, HSV-1(KOS)-, and HSV-1(vBS $\Delta 27)$-infected $(\mathrm{MOI}=5)$. At $6 \mathbf{A}$ and $18 \mathbf{B}$ hpi, cells were fixed, prepared for indirect immunofluoresence using anti-Bax antibodies, and the num-

ber $(\%)$ of apoptotic cells were determined as described in Material and Methods. DNA and mitochondria were detected by fluorescence microscopy following Hoechst and MitoTracker (MitoT) staining, respectively. Magnification $(\times 100)$ 


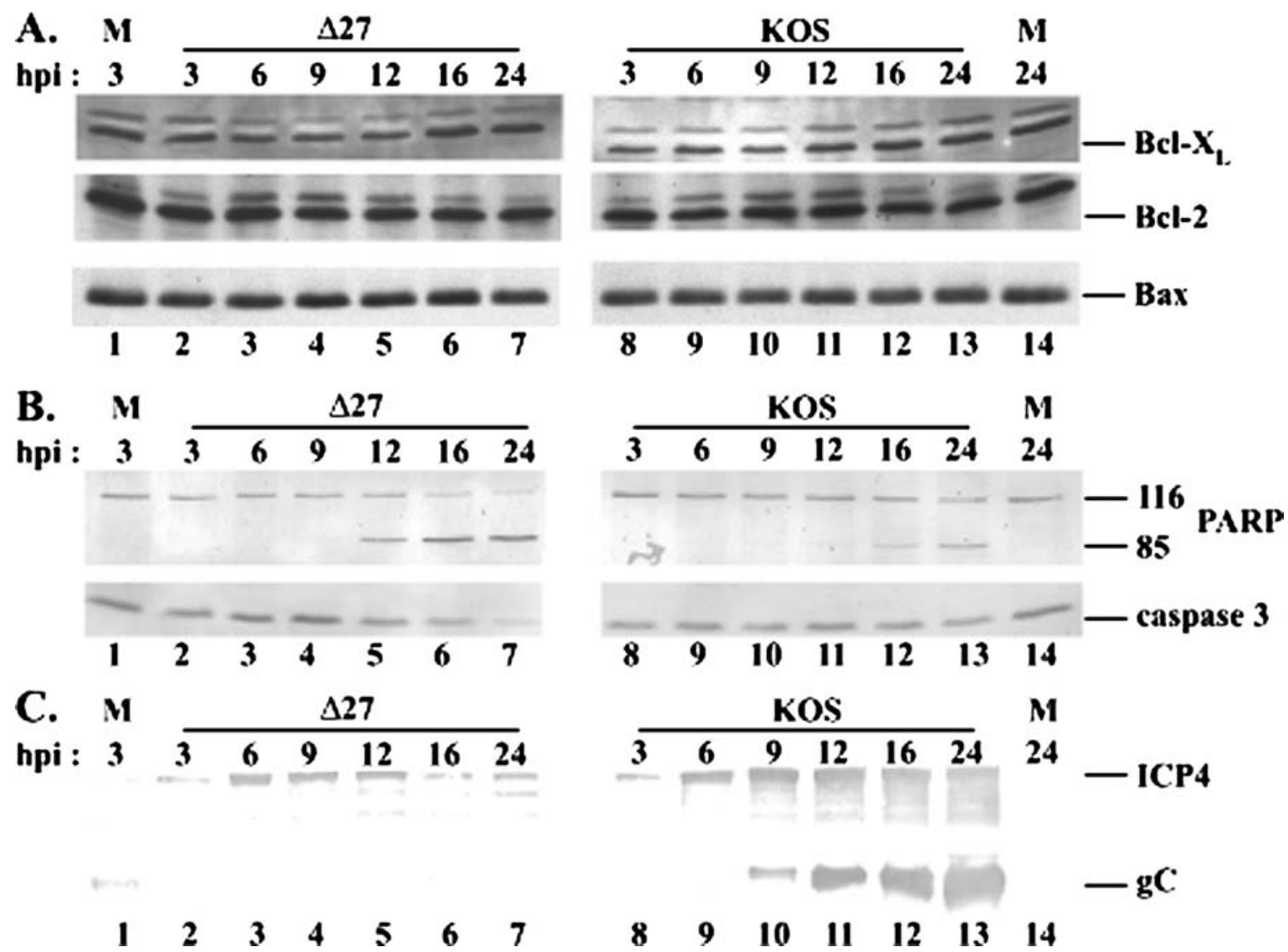

Fig. $8 \mathrm{Bcl}-\mathrm{X}_{\mathrm{L}}, \mathrm{Bcl}-2$, and $\mathrm{Bax}$ protein levels remain unchanged throughout vBS $\triangle 27$ and KOS infection. Wild type HSV-1(KOS)- and $\mathrm{HSV}(\mathrm{vBS} \Delta 27)$-infected $(\mathrm{MOI}=10) \mathrm{HEp}-2$ cell extracts were prepared at 3-24 hpi, separated in a denaturing gel, transferred to nitrocel-

Therefore, it was expected that the ICP22 signal is lower in the infected cells not expressing ICP27 (red only). These results indicate that expression of ICP27 in trans makes the defective virus less effective at inducing apoptosis.

In previously published work from our laboratory, we used a panel of mutant recombinant viruses carrying point mutations or partial deletions in specific regions of ICP27 to show that the accumulation of early and leaky-late viral proteins which are regulated by ICP27 correlates with the prevention of apoptosis [35]. Taken together, these data indicate that ICP27 itself is not responsible for the antiapoptotic activity but rather it promotes the expression of either another viral protein(s) or a cellular factor(s) which has antiapoptotic function during infection.

\section{Discussion}

While it is well-known that HSVs modulate apoptosis [11, $12,46]$, details of the triggering and prevention mechanisms still remain fragmented. In this report, we attempted to gain a more global picture of what happens during HSV-1 infec-

lulose, and probed with anti-Bcl- $\mathrm{X}_{\mathrm{L}}$, -Bcl-2, -Bax, -PARP, -caspase-3, $-\mathrm{ICP} 4$, and - $\mathrm{gC}$ antibodies as described in Materials and Methods. Control mock-infected (M) cells at 24 hpi are shown

tion. We have found that HSV-1-dependent apoptosis occurs through the apoptosome upon translocation of Bax to mitochondria, triggering of the release of cytochrome $c$ from mitochondria, and the subsequent activation of caspase-9 in human epithelial HEp-2 cells. Our key findings may be summarized as follows.

HSV-1-dependent apoptosis occurs through the mitochondrial pathway

This conclusion is based on our observation that complete caspase- 9 but not caspase- 8 cleavage is detected during infection with an apoptotic HSV-1 strain. Caspase-9 cleavage during apoptotic HSV-1 infection directly correlates with the presence of other apoptotic features, such as PARP processing, while caspase- 3 cleavage is biphasic. Partial caspase3 cleavage occurs at early times following infection with wild type HSV-1 but PARP is intact. Significant caspase-3 cleavage is observed at later times only in cases where HSV1 fails to prevent apoptosis and this directly corresponds with detectable PARP processing. We previously reported that caspase 3 is activated at early times following infec- 


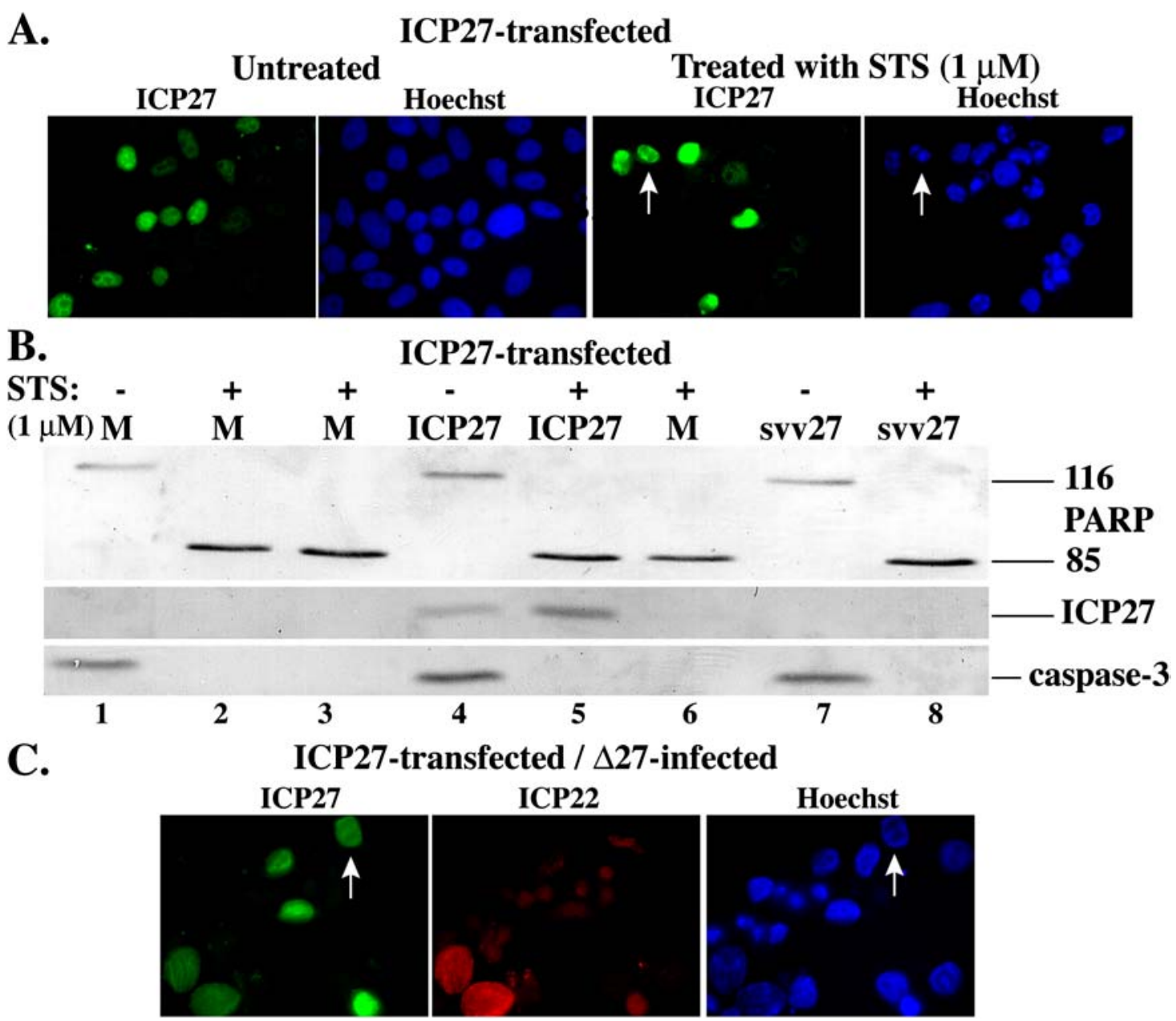

Fig. 9 ICP27 protein alone does not prevent apoptosis. HEp-2 cells were transfected with plasmids expressing ICP27 A, B, C or simian varicella virus ICP27 (svv27) $\mathbf{B}$ in the presence $(+)$ or absence $(-)$ of STS (A, B). (A). Cells were stained with Hoechst, fixed, and prepared for indirect immunofluoresence using anti-ICP27 antibody as described in materials and Methods. B. Cell extracts were prepared, separated in a denaturing gel, transferred to nitrocellulose, and probed with antiPARP, -caspase-3, and -ICP27 antibodies as described in Materials

tion with wild type virus [17] but subsequently synthesized infected cell proteins act to inhibit the apoptotic process. However, we cannot exclude the possibility that although caspase 3 is activated in wild type virus-infected cells, its activity is held in check by cellular IAPs. Since we do not detect caspase-9 cleavage with wild type HSV-1, its partial activation of caspase-3 likely occurs independent of apoptosis induction through the mitochondrial pathway. The addition of the caspase- 8 inhibitor seemed to reduce caspase- 3 cleavage in apoptotic HSV-1-infected cells (Fig. 3), raising the intriguing possibility that undetectable but relevant caspase- 8 activity may be involved. That caspase- 8 appears to remain inactive throughout HSV-1-dependent apoptosis is somewhat surprising since HveA, a receptor for HSV-1, is member of the TNF-receptor family [47]. It is therefore and Methods. Controls included plasmid vector only (M) transfected cells. C. ICP27-transfected cells were infected with HSV-1(vBS $\Delta 27)$ $(\mathrm{MOI}=5)$ and at $18 \mathrm{hpi}$, the cells were fixed, prepared for indirect immunofluoresence using anti-ICP27 and-ICP22 antibodies. DNA was detected by fluorescence microscopy following Hoechst staining. Magnification $(\times 100)$. Arrows mark representative cells expressing transfected ICP27

conceivable that HSV-1 produces a factor that might immediately preclude receptor-mediated activation of caspase- 8 .

Cytochrome $c$ release from mitochondria during HSV-1-dependent apoptosis occurs without caspase cleavage

The addition of pancaspase inhibitor to cells infected with an apoptotic HSV-1 virus precludes the development of all overt features of apoptosis and leads to increased accumulation of viral polypeptides but mitochondrial cytochrome $c$ is still released into the cytoplasm. There are at least two significant implications of these observations. First, these results indicate that HSV-1-stimulated apoptosis is caspase-dependent. Complete caspase- 9 and caspase- 3 cleavage, therefore, 
defines HSV-1-dependent apoptosis. These results are in accordance with a previous report that the replication-defective (ICP4- and $\mathrm{U}_{\mathrm{S}} 3$-null) HSV-1(d120) virus induces apoptosis through a caspase-dependent pathway [34] leading to cell shrinkage, chromatin condensation, cytochrome $c$ release, and chromosomal DNA fragmentation in HEp- 2 cells. Second, HSV-1 induced cytochrome $c$ release occurs in a manner that does not require caspase activation. Thus, apoptotic HSVs initiate but cannot block cytochrome $c$ release, indicating that infected cell factor(s) are required to prevent this process. Based on these findings, one might also expect that HSV-dependent apoptosis would only occur following mitochondrial release of smac $[48,49]$ and the subsequent decrease in levels of cellular IAPs reviewed in [50]. The model that emerges is one in which complete caspase activation during HSV-1-dependent apoptosis is a consequence of cytochrome $c$ release from mitochondria. This explains the observation that ectopic overexpression of Bcl-2 which prevents cytochrome $c$ release can decrease HSV-1-dependent apoptosis [23]. One implication of these findings is that cross-talk from the extrinsic to the intrinsic pathway is unlikely to be the mechanism through which cells undergo HSV-1-dependent apoptosis.

HSV-1 may preclude virus-induced apoptosis by targeting proapoptotic Bax

To our knowledge, our findings represent the first proposal that the mechanism through which HSV-1 prevents virusinduced apoptosis from killing infected cells is by blocking proapoptotic Bax from relocating to mitochondria. However, there have been earlier indications that HSV-1 might act on cellular factors to aid in the prevention of apoptosis. It was reported that in the absence of other viral proteins, the proapoptotic bcl-2 family member, BAD, was stabilized and inactivated by the viral $\mathrm{U}_{\mathrm{S}} 3$ kinase [27, 51]. In these studies, caspase- 3 activation and DNA fragmentation in rabbit skin cells, triggered by infection with a baculovirus overexpressing BAD (bac-BAD), was decreased after also overexpressing $\mathrm{U}_{\mathrm{S}} 3$ from another baculovirus vector $\left(\right.$ bac- $\left.\mathrm{U}_{\mathrm{S}} 3\right)$. $\mathrm{BAD}$ migration in acrylamide gel electrophoresis was retarded in lysates from cells infected with bac- $\mathrm{U}_{\mathrm{S}} 3$ prior to infection with bac-BAD as compared to controls. Cartier et al. showed that overexpression of $\mathrm{U}_{\mathrm{S}} 3$ in stable cell lines can block HSV1 - and chemically-induced apoptosis and prevent caspase-3 and -9 activation [52]. In these studies, when $U_{S} 3$ is overexpressed, Bad is phosphorylated. Unfortunately, these results are not without controversy. Although $\mathrm{U}_{\mathrm{S}} 3$ might induce phosphorylation of Bad in these systems, it seems that Bad phosphorylation is dispensable for $\mathrm{U}_{\mathrm{S}} 3$ 's accessory $[11,12$, 17] antiapoptotic function [53]. Another transient expression study has concluded that $U_{\mathrm{S}} 3$ exerts its antiapoptotic effects downstream of the mitochondria [54]. Thus, while our stud- ies have defined the point at which wild type HSV-1 blocks virus-induced apoptosis during productive infection, roles of viral proteins, especially $\mathrm{U}_{\mathrm{S}} 3$, in this process remain unresolved. The development of appropriate molecular genetic and biochemical systems will be needed to address these questions.

\section{Conclusion}

The addition of either a pancaspase inhibitor or caspase9-specific inhibitor prevented cells infected with an apoptotic HSV-1 virus from undergoing cell death. Thus, HSV1-dependent apoptosis proceeds through the mitochondrial apoptotic pathway. However, the pancaspase inhibitor did not prevent the release of cytochrome $c$ from mitochondria, implying that caspase activation is not required for this induction of apoptosis by HSV-1. Importantly, Bax accumulated at mitochondria during apoptotic, but not wild type HSV-1 infection. These findings indicate that HSV-1 blocks apoptosis by precluding mitochondrial cytochrome $c$ release in a caspase-independent manner and suggest Bax as a target in HSV-1-infected human epithelial cells.

Acknowledgments We thank Jennifer O'Toole (Mount Sinai) for expert cell culture assistance and Scott Henderson for expert technical advice concerning confocal microscopy. These studies were supported in part by grants from the United States Public Health Service (AI38873 and AI48582 to J.A.B.). L.E.P. was a predoctoral trainee and was supported in part by a United States Public Health Service Institutional Research Training Award (GM 08553).

\section{References}

1. Kerr JF, Wyllie AH, Currie AR (1972) Apoptosis: a basic biological phenomenon with wide-ranging implications in tissue kinetics. $\mathrm{Br}$ J Cancer 26(4):239-257

2. Kerr FR, Harmon BV (1991) Definition and incidence of apoptosis: An historical perspective. In: Tomei LD, Cope FO (ed.) Apoptosis: The molecular basis of cell death. Cold Spring Harbor Laboratory, Cold Spring Harbor, NY, p 5-29

3. Sanfilippo CM, Blaho JA (2003) The facts of death. Int Rev Immunol 22(5-6):327-340

4. Green DR (1998) Apoptotic pathways: The roads to ruin. Cell 94:695-698

5. Sun XM, MacFarlane M, Zhuang J, Wolf BB, Green DR, Cohen GM (1999) Distinct caspase cascades are initiated in receptor-mediated and chemical-induced apoptosis. J Biol Chem 274(8):5053-5060

6. Ashkenazi A, Dixit VM (1998) Death receptors: Signaling and modulation. Science 281(5381):1305-1308

7. Li H, Zhu H, Xu CJ, Yuan J (1998) Cleavage of BID by caspase 8 mediates the mitochondrial damage in the Fas pathway of apoptosis. Cell 94(4):491-501

8. Luo X, Budihardjo I, Zou H, Slaughter C, Wang X (1998) Bid, a $\mathrm{Bcl} 2$ interacting protein, mediates cytochrome $c$ release from mitochondria in response to activation of cell surface death receptors. Cell 94(4):481-490 
9. Korsmeyer SJ, Wei MC, Saito M, Weiler S, Oh KJ, Schlesinger PH (2000) Pro-apoptotic cascade activates BID, which oligomerizes Bak or Bax into pores that result in the release of cytochrome $c$. Cell Death Differ 7(12):1166-1173

10. Koyama AH, Adachi A, Irie H (2003) Physiological significance of apoptosis during animal virus infection. Int Rev Immunol 22(56):341-359

11. Goodkin ML, Morton ER, Blaho JA (2004) Herpes simplex virus infection and apoptosis. Int Rev Immunol 23(1-2):141-172

12. Aubert M, Blaho JA (2001) Modulation of apoptosis during herpes simplex virus infection in human cells. Microbes and Infection; 10.

13. Sanfilippo CM, Chirimuuta FN, Blaho JA (2004) Herpes simplex virus type 1 immediate-early gene expression is required for the induction of apoptosis in human epithelial HEp-2 cells. J Virol 78(1):224-239

14. Galvan V, Roizman B (1998) Herpes simplex virus 1 induces and blocks apoptosis at multiple steps during infection and protects cells from exogenous inducers in a cell- type-dependent manner. Proc Natl Acad Sci USA 95(7):3931-3936

15. Aubert M, Blaho JA (2003) Viral oncoapoptosis of human tumor cells. Gene Ther 10(17):1437-1445

16. Nguyen ML, Kraft RM, Blaho JA (2005) African green monkey kidney Vero cells require de novo protein synthesis for efficient herpes simplex virus 1-dependent apoptosis. Virology 336(2):274290

17. Aubert M, O’Toole J, Blaho JA (1999) Induction and prevention of apoptosis in human HEp-2 cells by herpes simplex virus type 1 . J Virol 73(12):10359-10370

18. Koyama AH, Miwa Y (1997) Suppression of apoptotic DNA fragmentation in herpes simplex virus type 1-infected cells. J Virol 71(3):2567-2571

19. Leopardi R, Roizman B (1996) The herpes simplex virus major regulatory protein ICP4 blocks apoptosis induced by the virus or by hyperthermia. Proc Natl Acad Sci USA 93(18):9583-9587

20. Jerome KR, Chen Z, Lang R, Torres MR, Hofmeister J, Smith S, et al (2001) HSV and glycoprotein J inhibit caspase activation and apoptosis induced by granzyme B or Fas. J Immunol 167(7):39283935

21. Jerome KR, Tait JF, Koelle DM, Corey L (1998) Herpes simplex virus type 1 renders infected cells resistant to cytotoxic Tlymphocyte-induced apoptosis. J Virol 72(1):436-441

22. Goodkin ML, Ting AT, Blaho JA (2003) NF-kappaB is required for apoptosis prevention during herpes simplex virus type 1 infection. J Virol 77(13):7261-7280

23. Galvan V, Brandimarti R, Munger J, Roizman B (2000) Bcl-2 blocks a caspase-dependent pathway of apoptosis activated by herpes simplex virus 1 infection in HEp-2 cells. J Virol 74(4):19311938

24. Gregory D, Hargett D, Holmes D, Money E, Bachenheimer SL (2004) Efficient replication by herpes simplex virus type 1 involves activation of the IkappaB kinase-IkappaB-p65 pathway. J Virol 78(24):13582-13590

25. Perng GC, Jones C, Ciacci-Zanella J, Stone M, Henderson G, Yukht A et al (2000) Virus-induced neuronal apoptosis blocked by the herpes simplex virus latency-associated transcript. Science 287(5457):1500-1503

26. Ahmed M, Lock M, Miller CG, Fraser NW (2002) Regions of the herpes simplex virus type 1 latency-associated transcript that protect cells from apoptosis in vitro and protect neuronal cells in vivo. J Virol 76(2):717-729

27. Munger J, Chee AV, Roizman B (2001) The U(S)3 protein kinase blocks apoptosis induced by the d120 mutant of herpes simplex virus 1 at a premitochondrial stage. J Virol 75(12):5491-5497

28. Jerome KR, Fox R, Chen Z, Sears AE, Lee H, Corey L (1999) Herpes simplex virus inhibits apoptosis through the action of two genes, Us5 and Us3. J Virol 73(11):8950-8957

29. Langelier Y, Bergeron S, Chabaud S, Lippens J, Guilbault C, Sasseville AM et al (2002) The R1 subunit of herpes simplex virus ribonucleotide reductase protects cells against apoptosis at, or upstream of, caspase-8 activation. J Gen Virol 83(Pt 11):27792789

30. Koyama AH, Adachi A (1997) Induction of apoptosis by herpes simplex virus type 1. J Gen Virol 78(Pt 11):2909-2912

31. Soliman TM, Sandri-Goldin RM, Silverstein SJ (1997) Shuttling of the herpes simplex virus type 1 regulatory protein ICP27 between the nucleus and cytoplasm mediates the expression of late proteins. J Virol 71(12):9188-9197

32. DeLuca NA, McCarthy AM, Schaffer PA (1985) Isolation and characterization of deletion mutants of herpes simplex virus type 1 in the gene encoding immediate-early regulatory protein ICP4. J Virol 56(2):558-570

33. Aubert M, Blaho JA (1999) The herpes simplex virus type 1 regulatory protein ICP27 is required for the prevention of apoptosis in infected human cells. J Virol 73(4):2803-2813

34. Galvan V, Brandimarti R, Roizman B (1999) Herpes simplex virus 1 blocks caspase-3-independent and caspase-dependent pathways to cell death. J Virol 73(4):3219-3226

35. Aubert MA, Rice SA, Blaho JA (2001) Accumulation of herpes simplex virus type 1 early and leaky-late proteins correlates with apoptosis prevention in infected human HEp-2 cells. J Virol 75(2):1013-1030

36. Gray WL, Starnes B, White MW, Mahalingam R (2001) The DNA sequence of the simian varicella virus genome. Virology 284(1):123-130

37. Pomeranz LE, Blaho JA (2000) Assembly of infectious Herpes simplex virus type 1 virions in the absence of full-length VP22. J Virol 74(21):10041-10054

38. Blaho JA, Zong CS, Mortimer KA (1997) Tyrosine phosphorylation of the herpes simplex virus type 1 regulatory protein ICP22 and a cellular protein which shares antigenic determinants with ICP22. J Virol 71(12):9828-9832

39. Juin P, Hueber AO, Littlewood T, Evan G (1999) c-Myc-induced sensitization to apoptosis is mediated through cytochrome $c$ release. Genes Dev 13(11):1367-1381

40. Pomeranz LE, Blaho JA (1999) Modified VP22 localizes to the cell nucleus during synchronized herpes simplex virus type 1 infection. J Virol 73(8):6769-6781

41. Kraft RM, Nguyen ML, Yang XH, Thor AD, Blaho JA (2006) Caspase 3 activation during herpes simplex virus 1 infection. Virus Res 120(1-2):163-175

42. Lakhani SA, Masud A, Kuida K, Porter GA Jr, Booth CJ, Mehal WZ et al (2006) Caspases 3 and 7: key mediators of mitochondrial events of apoptosis. Science 311(5762):847-851

43. Li P, Nijhawan D, Budihardjo I, Srinivasula SM, Ahmad M, Alnemri ES et al (1997) Cytochrome $c$ and dATP-dependent formation of Apaf-1/caspase-9 complex initiates an apoptotic protease cascade. Cell 91(4):479-489

44. Wei MC, Zong WX, Cheng EH, Lindsten T, Panoutsakopoulou V, Ross AJ et al (2001) Proapoptotic BAX and BAK: A requisite gateway to mitochondrial dysfunction and death. Science 292(5517):727-730

45. Saito M, Korsmeyer SJ, Schlesinger PH (2000) BAX-dependent transport of cytochrome $c$ reconstituted in pure liposomes. Nat Cell Biol 2(8):553-555

46. Yedowitz JC, Blaho JA (2005) Herpes simplex virus 2 modulates apoptosis and stimulates NF-kappaB nuclear translocation during infection in human epithelial HEp-2 cells. Virology 342(2):297310

47. Montgomery RI, Warner MS, Lum BJ, Spear PG (1996) Herpes simplex virus-1 entry into cells mediated by a novel member of the TNF/NGF receptor family. Cell 87(3):427-436 
48. Deng Y, Lin Y, Wu X (2002) TRAIL-induced apoptosis requires Bax-dependent mitochondrial release of Smac/DIABLO. Genes Dev 16(1):33-45

49. Kandasamy K, Srinivasula SM, Alnemri ES, Thompson CB, Korsmeyer SJ, Bryant JL et al (2003) Involvement of proapoptotic molecules Bax and Bak in tumor necrosis factor-related apoptosis-inducing ligand (TRAIL)-induced mitochondrial disruption and apoptosis: Differential regulation of cytochrome $c$ and Smac/DIABLO release. Cancer Res 63(7):1712-1721

50. Schuler M, Green DR (2001) Mechanisms of p53-dependent apoptosis. Biochem Soc Trans 29(Pt 6):684-688

51. Munger J, Roizman B (2001) The US3 protein kinase of herpes simplex virus 1 mediates the posttranslational modification of BAD and prevents BAD-induced programmed cell death in the absence of other viral proteins. Proc Natl Acad Sci USA 98(18):1041010415

52. Cartier A, Komai T, Masucci MG (2003) The Us3 protein kinase of herpes simplex virus 1 blocks apoptosis and induces phosporylation of the Bcl-2 family member Bad. Exp Cell Res 291(1):242250

53. Benetti L, Munger J, Roizman B (2003) The herpes simplex virus 1 US3 protein kinase blocks caspase-dependent double cleavage and activation of the proapoptotic protein BAD. J Virol 77(11):65676573

54. Ogg PD, McDonell PJ, Ryckman BJ, Knudson CM, Roller RJ (2004) The HSV-1 Us3 protein kinase is sufficient to block apoptosis induced by overexpression of a variety of Bcl-2 family members. Virology 319(2):212-224 